\title{
Statistical Analysis of Breast Cancer Cases in University College Hospital (UCH) Ibadan, Nigeria
}

\author{
Oluwadamisi Tayo-Ladega \\ CEO His Marvellous Grace Support Foundation, Nigeria; PHD STudent, Bangor University, UK \\ *Corresponding Author: Oluwadamisi Tayo-Ladega, CEO His Marvellous Grace Support \\ Foundation, Nigeria; PHD STudent, Bangor University, UK
}

\begin{abstract}
This study examines the statistical analysis of breast cancer reported in the University College Hospital $(U C H)$ Ibadan, Nigeria. It is a commonest cause of cancer-related mortality among women all over the world including Nigeria. This study evaluated different forecasting model using reported cases of breast cancer data from the University College Hospital (UCH) Ibadan. Yearly data from 2008 to 2017 were collected and used to forecast. The forecast model used in the analysis included single moving average method ( $n=2, n=3, n=4, n=5, n=6, n=7, n=8, n=9, n=10$ ), simple exponential smoothing method $(\alpha=0.1, \alpha=0.2, \alpha=0.3, \alpha=0.4, \alpha=0.5, \alpha=0.6, \alpha=0.7, \alpha=0.8, \alpha=0.9)$ and Ordinary Least Square (OLS) regression The most appropriate forecasting method was determined on the basis of accuracy. In this research, the common accuracy method was used: mean absolute deviation (MAD). The study found that two yearly moving average $(n=2)$ and the yearly moving average $(n=3)$ are most accurate, as they has lowest value of Mean Absolute Deviation (MAD); exponential smoothing, the smoothing constant of 0.9 appears to be the lowest value of Mean Absolute Deviation (MAD); and there is maximum error term and the explanation is very low; hence the prediction or forecast by OLS regression seems to be unreliable and that interpolated forecast produced by OLS regression cannot be suitable for extrapolation.
\end{abstract}

Keywords: Statistical analysis; Forecasting; Breast cancer; UCH Ibadan, Nigeria

\section{INTRODUCTION}

Breast cancer is a significant cause of cancerrelated mortality in women all over the world (Agboola et al., 2012). The incidence of breast cancer in women is rising across the globe (GLOBOCAN, 2012). A comparison of the World Health Organization's International Agency for Research On Cancer [IARC], latest two versions (GLOBOCAN, 2008 \& 2012) showed that the number of new cases increased from 12.7 million in 2008 to 14.1 million cases in 2012. Approximately 1.4 million women were diagnosed with breast cancer in 2012. There are 6.3 million women alive who have been diagnosed in the previous five years (Ferlay et al., 2010). Since the 2008 estimates, breast cancer incidence has increased by more than $20 \%$ while mortality has increased by $14 \%$.

GLOBOCAN (2012), predict that the total number of new breast cancer cases in women would increase to an alarming number of 22 million by 2025 . The mortality rate is expected to rise to 13 million at that rate. Hudis (2014) stated that a possible explanation for this observation are fourfold: a) Many countries now have resources to diagnose and report breast cancer more accurately;

b) Populations are growing;

c) Women around the world are living longer; and

d) There is a global trend towards weight gain and obesity, with a broad adoption of the Western lifestyle and diet.

Hudis (2014) therefore called for applying the strategies that were successfully used in the West to bringing down the mortality rate of breast cancer to the developing countries so as to save millions of lives. In Nigeria, GLOBOCAN (2012) reported 27,304 cases of breast cancer in women in for the year 2014. This figure amounted to $42.2 \%$ of all cases of cancer in women at that time, with a mortality of 13,960 cases. This figure amounts to $34.3 \%$ of deaths from cancer in women. The five-year prevalence prediction for Nigeria stands at 87,579 cases. This figure amounts to $53.1 \%$ of all cancers in women. The data of breast cancer in Nigeria show a significant disparity in the health outcomes of women living with breast cancer. 
Maxmen (2012) stated that many factors influence a woman's chances of survival, including how early the tumor was detected and the molecular profile of the tumor. Women diagnosed now are much more likely to survive than women in decades past (Fregene et al. 2005; Maxmen, 2012). This is because women are living longer each decade because of improvements in surgery, screening, chemotherapies, hormone and biologic therapies. Tumors that are discovered while still localized, grant patients the best prognosis. As cancer spreads, it often becomes increasingly difficult to cure (Maxmen, 2012). Incidentally, breast cancer can be tracked along the continuum of care at different stages by the application of effective strategies for prevention, early detection, treatment, and care (Yip et al., 2012).

With the estimated increase in the burden of breast cancer, urgent action is needed to understand the determinants of these health outcomes so as to arrest this trend. Such understanding can inform programs that will assist in the implementation of evidence-based strategies for prevention, early detection, diagnosis, treatment, and palliation of breast cancer in women, while making the best use of available resources. This study intends to explore the statistical trend of reported cases of breast cancer in Nigeria. Specifically, this study sets out to explore various quantitative forecasting techniques, evaluating the best techniques with the purpose of identifying the most accurate forecast.

According to Nijat, David, Peter, and Peter (2016), selecting the most suitable forecasting technique in planning is quite challenging, it that requires having a detailed record of past data and having a comprehensive analysis of empirical results. Recent research findings reveal that assessing the most suitable method of forecasting out of every other forecasting methods is referred to as the performance evaluation of forecasting models; it depends on the accuracy measures adopted.

Evaluating the performance of the forecasting method is very crucial, in the last three decades various accuracy measures have been adopted by many studies as an evaluation criterion. A number of different forecast accuracy measures for both regression and classification problems have been proposed by earlier researchers together with the comments and recommendations on the use of the relevant measures (Mahmou, 1984; Makridakis, 199;
Hyndman and Koehler, 2006; Sokolova and Lapalme, 2009; Power, 2011). The quantitative forecasting techniques evaluated in this study were single moving average, simple exponential smoothing, and trend analysis. The study is limited to the three forecasting methods because of the ease of use. The forecasting methods analyzed include: single moving average $(\mathrm{n}=2$, $\mathrm{n}=3, \mathrm{n}=4, \mathrm{n}=5, \mathrm{n}=6, \mathrm{n}=7, \mathrm{n}=8, \mathrm{n}=9, \mathrm{n}=10$ ) and simple exponential smoothing method $(\alpha$ $=0.1, \alpha=0.2, \alpha=0.3, \alpha=0.4, \alpha=0.5, \alpha=0.6, \alpha=0.7$, $\alpha=0.8, \alpha=0.9$ ). The accuracy of the forecasting method were mean Absolute Deviation (MAD), Mean Square Error (MSE), Root Mean Square Error (RMSE) and coefficient of reliability.

The Cancer Statistics Worldwide (2005) documented that worldwide; more than one million new cases of female breast cancer are diagnosed each year, making it the most commonly occurring disease in women, accounting for over $1 / 3$ of the estimated annual 4.7million cancer diagnosis in females and the second most common tumor after lung cancer in both sexes. It is also the most common female cancer in both developed and developing countries with $55 \%$ of it occurring in the developing countries. In addition, the annual worldwide incidences had almost doubled since 1975 and the prevalence and incidences increased with increasing age (Althuis, 2005).

Breast cancer is the most common cause of cancer-related deaths worldwide, and case fatality rates are highest in low-resource countries (Anderson et al., 2008; Ferlay et al., 2010). Over 411,000 deaths result from breast cancer annually, accounting for greater than $1.6 \%$ of female deaths from all causes (Anderson et al., 2008). The incidence of breast cancer in Nigeria has risen significantly (JedyAgba et al., 2012). The age-standardized incidence rate for breast cancer in the period from 1960 to 1969 was 13.7 per 100,000 . It rose to 24.7 per 100,000 by $1998-1999$; more or less a doubling of incidence over four decades or approximately $25 \%$ increase in rate per decade. The rate in $2009-2010$ was 54.3 per 100,000 . This represents a $100 \%$ increase in the last ten years (Jedy-Agba et al., 2012).

Despite the threat that breast cancer poses to public health especially in sub-Saharan Africa, few countries in the region have data on breast cancer incidence (Sylla \& Wild, 2012). Most of the breast cancer incidence data in Sub-Sahara Africa in recent times were based on reports from registries in The Gambia, Zimbabwe and 
Uganda (Curado et al., 2011). Jedy-Agba et al. (2012) reported that the incidence rate of breast cancer in their study was higher than that reported by GLOBOCAN's (2008) estimate of $38.7 \%$ per 100,000 . According to Forouzanfar (2011), the reported increasing incidence may be real, due to the prevalence of risk factors for these cancers.

Jedy-Agba et al. (2012) highlighted the need for high-quality regional cancer registries to serve a vast country like Nigeria to adequately inform policy and allocation of resources for breast cancer treatments. Cancer registries play a significant role in the design and monitoring of disease control activities and policies. Population-based cancer registries are the primary source of information in developed countries like Canada. In developed countries, the health care infrastructure enables the registration of quality cancer data. In low and middle-income countries, where medical facilities are limited or scarce, cancer registration data may be of low quality. According to Curado et al. (2009), high-quality data are necessary to guide cancer care and improvement of identified goals.

Afolayan et al. (2012) also alluded to the poverty of data and sparse literature review on the trends of breast cancer in Nigeria due to few existing cancer registries most of which are either hospital-based or pathology-based instead of the preferred population-based cancer registries. According to Boyle and Levin (2008), looking ahead with the rapidly rising cancer burden in low and middle-income countries, more high-quality incidence data are needed from regions and countries to establish the breast cancer burden and to monitor its evolution particularly in response to cancer control and care activities (Boyle \& Levin, 2008). Many studies (Afolayan et al., 2008; 2012; GLOBOCAN, 2012; Jedy-Agba et al., 2012) consistently reported and predicted increases in breast cancer incidence and mortality for Nigeria. In developed country like Canada, the Canadian Cancer Society reported that fewer Canadian women are dying from breast cancer than in the past. The Canadian Cancer Society reported a decrease by 42 percent since the peak in 1986 (Canadian Cancer Statistics, 2014). According to the Canadian Cancer Society, women in Canada, who are diagnosed with breast cancer, are living longer than ever before, with 5-year survival rates of 88 percent (Canadian Cancer Statistics, 2014). The situation in Nigeria is not the same.
There is a prediction of more than a $100 \%$ increase in incidence and mortality rates of breast cancer in Nigeria by 2030 (Jedy-Agba et al., 2012; Sylla et al., 2012). With the disparities in outcomes in breast cancer between developed and developing countries, it is imperative that action be taken to understand the causes of these differences and address them appropriately. Despite the reported cases of poor prognosis of breast cancer, there is a lack of research evidence precisely detailing the determinants of the observed high mortality rate, particularly in Nigeria. Afolayan et al. (2012) likewise noted the same observation. The current research study intends to make available quality data that can be used as baseline information to guide breast cancer care. This study will predict the occurrence of breast cancer in Nigeria from year 2019 to year 2040. It is expected that this prediction will prepare the concerned stakeholders into improving breast health care for women most especially those living with breast cancer in Nigeria.

The aim of this study is to analyze the forecast of reported cases of breast cancer in Nigeria within a period of ten years. The specific objectives of this research are to determine the interpolated forecast for reported cases of breast cancer in Nigeria using single moving average with different moving averages; to establish the interpolated forecast for reported cases of breast cancer in Nigeria using simple exponential smoothing with different smoothing constants; to examine the interpolated forecast for reported cases of breast cancer in Nigeria using ordinary least-squares (OLS) linear regression analysis; and to evaluate the interpolated forecast that will be most suitable for extrapolation.

\section{METHODOLOGY}

This study evaluated different forecasting model using reported cases of breast cancer data from the University College Hospital (UCH) Ibadan. Yearly data from 2008 to 2017 were collected and used to forecast. The forecast model used in the analysis included single moving average method $(\mathrm{n}=2, \mathrm{n}=3, \mathrm{n}=4, \mathrm{n}=5, \mathrm{n}=6, \mathrm{n}=7, \mathrm{n}$ $=8, \mathrm{n}=9, \mathrm{n}=10$ ), simple exponential smoothing method $(\alpha=0.1, \alpha=0.2, \alpha=0.3, \alpha$ $=0.4, \alpha=0.5, \alpha=0.6, \alpha=0.7, \alpha=0.8, \alpha=0.9)$ and Ordinary Least Square (OLS) regression The most appropriate forecasting method was determined on the basis of accuracy. In this research, the common accuracy method was used: mean absolute deviation (MAD). 
Model Specification for Single Moving Average

The single moving average method involves calculating the average of observations and then employing that average as the predictor for the next period (Adeniran and Stephens, 2018). The moving average method is highly dependent on $\mathrm{n}$, the number of terms selected for constructing the average.

The equation is as follows: $\mathrm{F}_{\mathrm{t}+1}=\left(\mathrm{Y}_{\mathrm{t}}+\mathrm{Y}_{\mathrm{t}-1}+\mathrm{Y}_{\mathrm{t}-2}\right.$ $\left.+\ldots \ldots+\mathrm{Y}_{\mathrm{t}-\mathrm{n}+1}\right) / \mathrm{n}$ Equation 1

Where:

$\mathrm{F}_{\mathrm{t}+1}=$ the forecast value for the next period;

$\mathrm{Y}_{\mathrm{t}}=$ the actual value at period $\mathrm{t}$;

$\mathrm{n}=$ the number of terms in the moving average

The optimal $\mathrm{n}$ value can be determined by the interactive model in the smallest error. In some method, the general approach has been to use MSE. In this study, the value of $\mathrm{n}$ would be 2, 3, $4,5,6,7,8,9$, and 10.

\section{Model Specification for Simple Exponential Smoothing}

This is the frequently encountered forecasting technique which largely overcomes the limitations of moving averages. This method involves the automatic weighting of past data with weights that decrease exponentially with time, i.e. the most current values receive the greatest weighting and the older observations receive a decreasing weighting. The exponential smoothing technique is a weighted moving average system and the underlying principle is that the New Forecast $=$ Old forecast $+a$ proportion of the forecast error (Lucey, 2007). The smoothing constant $(\alpha)$ can be between 0 and 1 . The higher value of $\alpha$ (i.e. the nearer to 1), the more sensitive the forecast becomes to current conditions; whereas the lower the value, the more stable the forecast will be by reacting less sensitively to current conditions (Lucey, 2007; Adeniran and Stephens, 2018; Adeniran, Kanyio, and Owoeye, 2018). Lucey (2007) state that an approximate equivalent of exponential smoothing constants (alpha values: $\alpha)$ and a number of period moving average respectively. The equation for the simple exponential smoothing method is:

$\mathrm{F}_{\mathrm{t}+1}=\alpha \mathrm{Y}_{\mathrm{t}-1}+(1-\alpha) \mathrm{F}_{\mathrm{t}-1}$

Equation 2

Where:

$F_{t+1}=$ forecast value for the next period,

$\mathrm{F}_{\mathrm{t}-1}=$ last period forecast,
$\mathrm{Y}_{\mathrm{t}-1}$ is the last period actual value,

$\alpha=$ the smoothing constant $(0<\alpha<1)$

The accuracy of the simple exponential smoothing method strongly depended on the optimal value of $(\alpha)$. In this study, the value of $\alpha$ will be $0.1,0.2,0.3,0.4,0.5,0.6,0.7,0.8$, and 0.9 .

\section{Model Specification for OLS Regression}

The most widely used mathematical method for performing both time-series and the causal quantitative forecast is regression analysis. This applies specific mathematical formulas to estimate forecast equations. These equations may then be used to forecast future activity by applying the equations to independent variables that may occur in the future. Regression equations come in many forms. The most common regression equation is one that represents a straight line. The method used to estimate the equation of a straight line that best represents either historical trends or causal relationships is known as ordinary least-squares (OLS) linear regression analysis.

Although based in sophisticated theories of statistics and calculus, OLS linear regression analysis tools are readily available on most personal computer spreadsheet software, SPSS, SAS, and a variety programming languages that may be used to create custom regression models. All that is required of the forecaster is to collect appropriate data, enter the data into a software program, and apply the regression tool. Although applying data to today's regression tools is quite simple, proper interpretation and use of regression results require at least a fundamental knowledge of regression modeling from a theoretical perspective. It is suggested that anyone who will actively participate in performing or interpreting quantitative forecast results, such as those found from regression analysis, seek additional knowledge in statistical modeling. This study adopts time-series forecast using OLS linear regression for further forecasting tools.

For model specification, the regression line is stated as $\mathrm{Y}=\mathrm{a}+\mathrm{Bx}$................. (Equation 3) which is used to generates interpolations and extrapolations.

$\mathrm{Y}=$ Breast cancer reported (Dependent variable),

$\mathrm{a}=$ Intercept.

$\mathrm{B}=$ Parameter/ slope

$\mathrm{x}=$ Time (Independent variable) 
The difference between raw data $(\mathrm{Y})$ and the interpolations can be seen on the line graph, and calculated by the coefficient of determination. If the difference is wide, it will result in a low coefficient of determination. The implication is that there will be no need for extrapolation; as the extrapolated forecasts cannot be reliable. But if the difference is minimal, it will result in a high coefficient of determination. The implication is that the interpolated forecast will lead to extrapolations.

For the purpose of achieving the regression line, the following equations must be achieved:

$$
\begin{aligned}
& \Sigma \mathrm{y}=\mathrm{na}+\Sigma \mathrm{xb} \ldots \ldots \ldots \ldots \ldots . . .(\text { Equation } 4) \\
& \Sigma \mathrm{xy}=\Sigma \mathrm{xa}+\Sigma \mathrm{x}^{2} \mathrm{~b} \ldots \ldots \ldots \ldots \ldots \ldots . . . . .(\text { Equation 5) } \\
& \text { Model Specification for Forecasting Error }
\end{aligned}
$$

\section{a. Mean Absolute Deviation}

Mean Absolute Deviation (MAD) is a common method for measuring overall forecast error. The value is computed by dividing the sum of the absolute values of the individual forecast error by the sample size (the number of forecast periods). The equation is:

$\operatorname{MAD}=\frac{\sum_{\mathrm{t}=1}^{\mathrm{n}}(\mathrm{Yt}-\mathrm{Ft})}{\mathrm{n}}$

Where:

$\mathrm{Y}_{\mathrm{t}}=$ the actual value in time period $\mathrm{t}$

$\mathrm{F}_{\mathrm{t}}=$ the forecast value in time period $\mathrm{t}$

$\mathrm{n}=$ the number of periods

$F_{t}=$ the forecast value in time period $t$

$\mathrm{n}=$ the number of periods

b. Coefficient of determination $\left(\mathrm{R}^{2}\right)$

The difference between the true line and the observed line can be seen on the line graph and calculated by the coefficient of determination $\mathrm{R}^{2}$. If the difference of lines otherwise referred to as error term is wide, it will result to a low coefficient of determination. The implication is that the predictions of the forecast cannot be reliable. But if the error term is minimal, it will result to a high coefficient of determination. The implication is that the predictions of forecast will be reliable.

$\mathrm{R}^{2}=\frac{(Y E-\bar{Y})^{2}}{(y-\bar{Y})^{2}}$
Where:

$\overline{\mathrm{Y}}=\frac{\Sigma \mathrm{y}}{n} ; \mathrm{YE}=$ Forecast $(\mathrm{Y})$

\section{Evaluation of Forecasting Method}

In this study, the most appropriate forecasting method was selected on the basis of the level of accuracy and ease of use. The various forecasting method used to forecast, the accuracy of the forecasting method was assessed using mean absolute deviation (MAD), and Coefficient of determination is the reliability of forecast derived from interpolated forecast. The difference between the extrapolated forecast and interpolated forecast can be seen on the line graph often referred to as coefficient of determination $\mathrm{R}^{2}$. If the difference is wide, it will result to a low coefficient of determination which implies that the predictions of extrapolated demand forecast cannot be reliable. But if minimal, it will result to a high coefficient of determination which implies that the predictions of extrapolated forecast will be reliable.

\section{RESULTS AND DISCUSSIONS}

The results will be in the form of the objectives as stated: to determine the interpolated forecast for reported cases of breast cancer in Nigeria using single moving average with different moving averages; to establish the interpolated forecast for reported cases of breast cancer in Nigeria using simple exponential smoothing with different smoothing constants; to examine the interpolated forecast for reported cases of breast cancer in Nigeria using ordinary leastsquares (OLS) linear regression analysis; and to evaluate the interpolated forecast that will be most suitable for extrapolation.

From Table 1 and Figure 1, there is irregular fluctuation of trend regarding breast cancer occurrence in Nigeria. Also there seems to be high rate of breast cancer occurrence in the second and third quarters of year 2008; second quarter of year 2009; second and third quarters of year 2010; second and third quarters of year 2011; third quarter of year 2012; second and third quarters of year 2013, first and second quarters of year 2014; first quarter in year 2015; first quarter in the year 2016; and second, third quarters in year 2017. It is important to note that because of the unpredictability of trend displayed on line graph, there is need for critical analysis to determine a suitable method of forecast. 
Statistical Analysis of Breast Cancer Cases in University College Hospital (UCH) Ibadan, Nigeria

Table1. Record of breast cancer from year 2008 to 2017 in Nigeria

\begin{tabular}{|c|c|c|c|}
\hline YEAR & Quarter & No of Cancer Victims & Percentage Change \\
\hline \multirow[t]{4}{*}{ YR 2008} & Q1 & 108 & \\
\hline & Q2 & 128 & 15.625 \\
\hline & Q3 & 157 & 18.47134 \\
\hline & Q4 & 108 & -45.3704 \\
\hline \multirow[t]{4}{*}{ YR2009 } & Q1 & 99 & -9.09091 \\
\hline & $\mathrm{Q} 2$ & 105 & 5.714286 \\
\hline & Q3 & 74 & -41.8919 \\
\hline & Q4 & 96 & 22.91667 \\
\hline \multirow[t]{4}{*}{ YR 2010} & Q1 & 145 & 33.7931 \\
\hline & Q2 & 128 & -13.2813 \\
\hline & Q3 & 152 & 15.78947 \\
\hline & Q4 & 108 & -40.7407 \\
\hline \multirow[t]{4}{*}{ YR 2011} & Q1 & 90 & -20 \\
\hline & $\mathrm{Q} 2$ & 118 & 23.72881 \\
\hline & Q3 & 116 & -1.72414 \\
\hline & Q4 & 83 & -39.759 \\
\hline \multirow[t]{4}{*}{ YR 2012} & Q1 & 93 & 10.75269 \\
\hline & Q2 & 92 & -1.08696 \\
\hline & Q3 & 120 & 23.33333 \\
\hline & Q4 & 97 & -23.7113 \\
\hline \multirow[t]{4}{*}{ YR 2013} & Q1 & 112 & 13.39286 \\
\hline & Q2 & 99 & -13.1313 \\
\hline & Q3 & 100 & 1 \\
\hline & Q4 & 78 & -28.2051 \\
\hline \multirow[t]{4}{*}{ YR 2014} & Q1 & 130 & 40 \\
\hline & Q2 & 121 & -7.43802 \\
\hline & Q3 & 87 & -39.0805 \\
\hline & Q4 & 48 & -81.25 \\
\hline \multirow[t]{4}{*}{ YR 2015} & Q1 & 160 & 70 \\
\hline & Q2 & 69 & -131.884 \\
\hline & Q3 & 86 & 19.76744 \\
\hline & Q4 & 107 & 19.62617 \\
\hline \multirow[t]{4}{*}{ YR 2016} & Q1 & 114 & 6.140351 \\
\hline & Q2 & 95 & -20 \\
\hline & Q3 & 87 & -9.1954 \\
\hline & Q4 & 109 & 20.18349 \\
\hline \multirow[t]{4}{*}{ YR 2017} & Q1 & 107 & -1.86916 \\
\hline & $\mathrm{Q} 2$ & 141 & 24.11348 \\
\hline & Q3 & 157 & 10.19108 \\
\hline & $\mathrm{Q} 4$ & 164 & 4.268293 \\
\hline TOTAL & $\mathbf{N}=\mathbf{4 0}$ & 4388 & Percentage Change \\
\hline
\end{tabular}

Source: Authors computation (2019)

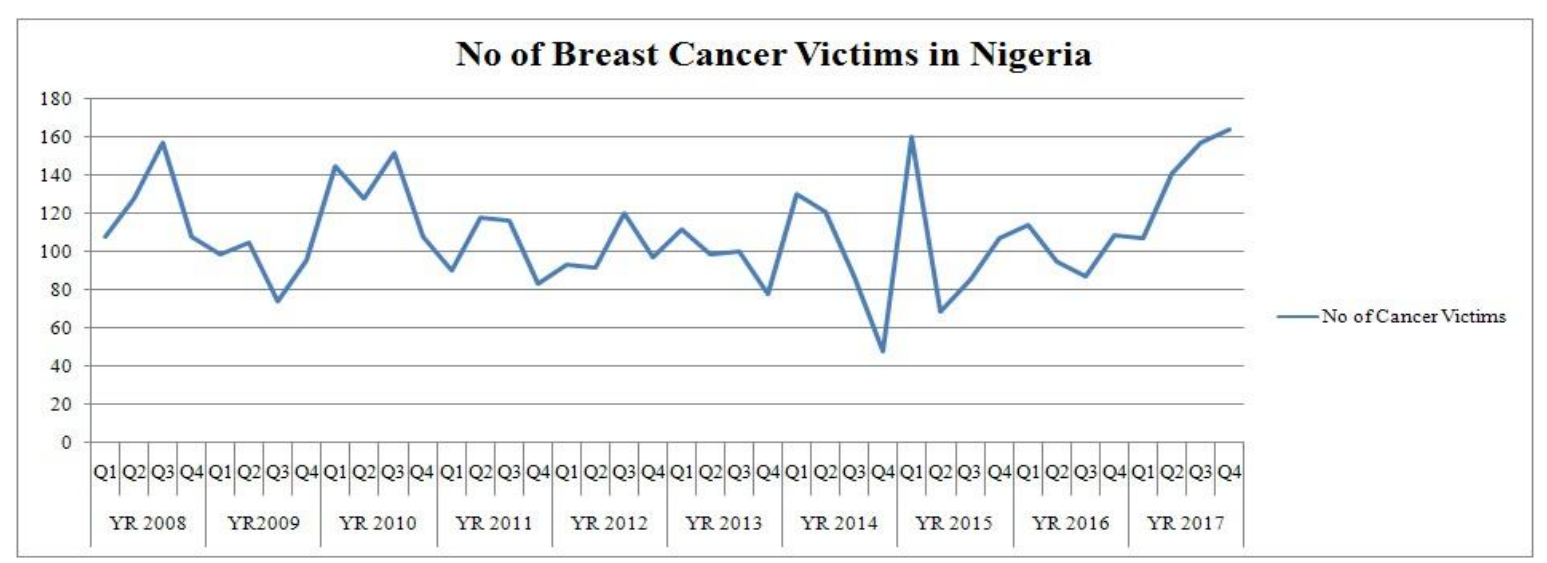

Figure1. Trend of breast cancer victims in Nigeria 
Interpolated Forecast of Breast Cancer Using Single Moving Average

Equation (1) in the model specification has to do with forecasting method using two, three, four, five, six, seven, eight, nine and ten years single moving averages. In order to derive the forecasts, the variables in the equation will be substituted with values, as shown in Table 2 and Figure 2. It was revealed that the lines of interpolated forecast and reported breast cancer have similar trend from the first quarter of 2008 to the fourth quarter of 2017 which might be easily predictable without any critical analysis, but there seems to be a situation of rising and falling which might not be easily predictable without critical analysis. To determine the forecast that seems close to the reported cases is quite difficult without evaluation technique. In the interpolated forecast, there were approximations because forecast cannot be usable in fraction.

Table2. Interpolated forecast using single moving averages

\begin{tabular}{|c|c|c|c|c|c|c|c|c|c|c|c|}
\hline YEAR & Quarter & $\begin{array}{c}\text { No of Cancer } \\
\text { Victims }\end{array}$ & $\mathrm{n}=\mathbf{2}$ & $\mathbf{n}=\mathbf{3}$ & $n=4$ & $n=5$ & $n=6$ & $\mathrm{n}=7$ & $\mathbf{n}=\mathbf{8}$ & $n=9$ & $\mathrm{n}=\mathbf{1 0}$ \\
\hline \multirow[t]{4}{*}{ YR 2008} & Q1 & 108 & & & & & & & & & \\
\hline & Q2 & 128 & & & & & & & & & \\
\hline & Q3 & 157 & 118 & & & & & & & & \\
\hline & $\mathrm{Q} 4$ & 108 & 143 & 131 & & & & & & & \\
\hline \multirow[t]{4}{*}{ YR2009 } & $\mathrm{Q} 1$ & 99 & 133 & 131 & 125 & & & & & & \\
\hline & Q2 & 105 & 104 & 121 & 123 & 120 & & & & & \\
\hline & Q3 & 74 & 102 & 104 & 117 & 119 & 118 & & & & \\
\hline & Q4 & 96 & 90 & 93 & 97 & 109 & 112 & 111 & & & \\
\hline \multirow[t]{4}{*}{ YR 2010} & Q1 & 145 & 85 & 92 & 94 & 96 & 107 & 110 & 109 & & \\
\hline & $\mathrm{Q} 2$ & 128 & 121 & 105 & 105 & 104 & 105 & 112 & 114 & 113 & \\
\hline & Q3 & 152 & 137 & 123 & 111 & 110 & 108 & 108 & 114 & 116 & 115 \\
\hline & $\mathrm{Q} 4$ & 108 & 140 & 142 & 130 & 119 & 117 & 114 & 113 & 118 & 119 \\
\hline \multirow[t]{4}{*}{ YR 2011} & Q1 & 90 & 130 & 129 & 133 & 126 & 117 & 115 & 113 & 113 & 117 \\
\hline & Q2 & 118 & 99 & 117 & 120 & 125 & 120 & 113 & 112 & 111 & 111 \\
\hline & Q3 & 116 & 104 & 105 & 117 & 119 & 124 & 120 & 114 & 113 & 112 \\
\hline & $\mathrm{Q} 4$ & 83 & 117 & 108 & 108 & 117 & 119 & 122 & 119 & 114 & 113 \\
\hline \multirow[t]{4}{*}{ YR 2012} & Q1 & 93 & 100 & 106 & 102 & 103 & 111 & 114 & 118 & 115 & 111 \\
\hline & $\mathrm{Q} 2$ & 92 & 88 & 97 & 103 & 100 & 101 & 109 & 111 & 115 & 113 \\
\hline & Q3 & 120 & 93 & 89 & 96 & 100 & 99 & 100 & 107 & 109 & 113 \\
\hline & Q4 & 97 & 106 & 102 & 97 & 101 & 104 & 102 & 103 & 108 & 110 \\
\hline \multirow[t]{4}{*}{ YR 2013} & Q1 & 112 & 109 & 103 & 101 & 97 & 100 & 103 & 101 & 102 & 107 \\
\hline & Q2 & 99 & 105 & 110 & 105 & 103 & 100 & 102 & 104 & 102 & 103 \\
\hline & Q3 & 100 & 106 & 103 & 107 & 104 & 102 & 99 & 102 & 103 & 102 \\
\hline & Q4 & 78 & 100 & 104 & 102 & 106 & 103 & 102 & 100 & 101 & 103 \\
\hline \multirow[t]{4}{*}{ YR 2014} & Q1 & 130 & 89 & 92 & 97 & 97 & 101 & 100 & 99 & 97 & 99 \\
\hline & $\mathrm{Q} 2$ & 121 & 104 & 103 & 102 & 104 & 103 & 105 & 104 & 102 & 100 \\
\hline & Q3 & 87 & 126 & 110 & 107 & 106 & 107 & 105 & 107 & 105 & 104 \\
\hline & $\mathrm{Q} 4$ & 48 & 104 & 113 & 104 & 103 & 103 & 104 & 103 & 105 & 104 \\
\hline \multirow[t]{4}{*}{ YR 2015} & Q1 & 160 & 68 & 85 & 97 & 93 & 94 & 95 & 97 & 97 & 99 \\
\hline & Q2 & 69 & 104 & 98 & 104 & 109 & 104 & 103 & 103 & 104 & 103 \\
\hline & Q3 & 86 & 115 & 92 & 91 & 97 & 103 & 99 & 99 & 99 & 100 \\
\hline & Q4 & 107 & 78 & 105 & 91 & 90 & 95 & 100 & 97 & 98 & 98 \\
\hline \multirow[t]{4}{*}{ YR 2016} & Q1 & 114 & 97 & 87 & 106 & 94 & 93 & 97 & 101 & 98 & 99 \\
\hline & Q2 & 95 & 111 & 102 & 94 & 107 & 97 & 96 & 99 & 102 & 100 \\
\hline & Q3 & 87 & 105 & 105 & 101 & 94 & 105 & 97 & 96 & 99 & 102 \\
\hline & Q4 & 109 & 91 & 99 & 101 & 98 & 93 & 103 & 96 & 95 & 97 \\
\hline \multirow[t]{4}{*}{ YR 2017} & Q1 & 107 & 98 & 97 & 101 & 102 & 100 & 95 & 103 & 97 & 96 \\
\hline & Q2 & 141 & 108 & 101 & 100 & 102 & 103 & 101 & 97 & 104 & 98 \\
\hline & Q3 & 157 & 124 & 119 & 111 & 108 & 109 & 109 & 106 & 102 & 108 \\
\hline & $\mathrm{Q} 4$ & 164 & 149 & 135 & 129 & 120 & 116 & 116 & 115 & 111 & 107 \\
\hline
\end{tabular}

Source: Authors' computation 
Statistical Analysis of Breast Cancer Cases in University College Hospital (UCH) Ibadan, Nigeria

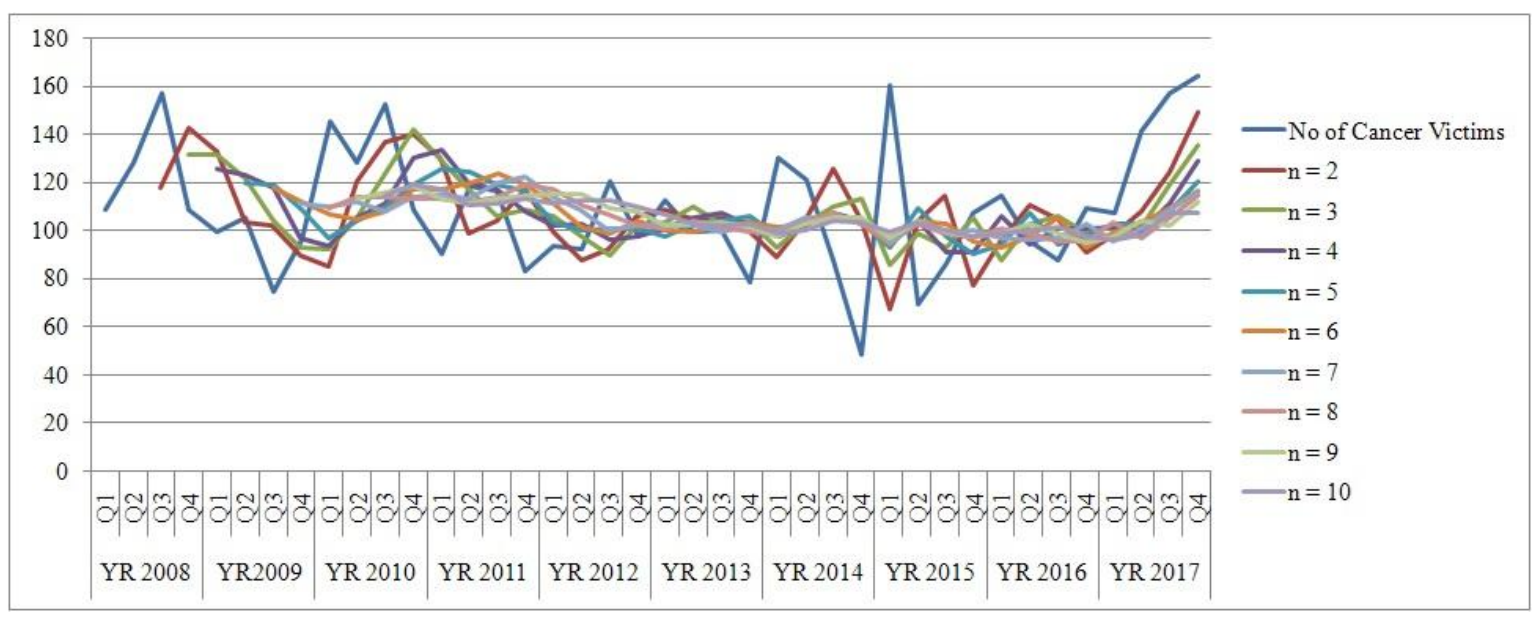

Figure2. Trend analysis of interpolated forecast of breast cancer using single moving average

Interpolated Forecast of Breast Cancer Using Simple Exponential Smoothing

Equation (2) in the model specification has to do with forecasting method using simple exponential smoothing with smoothing constants of $0.1,0.2,0.3,0.4,0.5,0.9,0.7,0.8$, and 0.9 . In order to derive the forecasts, the variables in the equation will be substituted with values, as shown in Table 3 and Figure 3. It was revealed that the lines of interpolated forecast and reported breast cancer have similar trend from the first quarter of 2008 to the fourth quarter of 2017 which might be easily predictable without any critical analysis, but there seems to be a situation of rising and falling which might not be easily predictable without critical analysis. To determine the forecast that seems close to the reported cases is quite difficult without evaluation technique. In the interpolated forecast, there were approximations because forecast cannot be usable in fraction.

Table3. Interpolated forecast using simple exponential smoothing

\begin{tabular}{|c|c|c|c|c|c|c|c|c|c|c|c|}
\hline YEAR & Quarter & No of Cancer Victims & $\alpha=0.1$ & $\alpha=0.2$ & $\alpha=0.3$ & $\alpha=0.4$ & $\alpha=0.5$ & $\alpha=0.6$ & $\alpha=0.7$ & $\alpha=0.8$ & $\alpha=0.9$ \\
\hline \multirow[t]{4}{*}{ YR 2008} & Q1 & 108 & & & & & & & & & \\
\hline & $\mathrm{Q} 2$ & 128 & 108 & 108 & 108 & 108 & 108 & 108 & 108 & 108 & 108 \\
\hline & Q3 & 157 & 110 & 112 & 114 & 116 & 118 & 120 & 122 & 124 & 126 \\
\hline & Q4 & 108 & 115 & 121 & 127 & 132 & 138 & 142 & 147 & 150 & 154 \\
\hline \multirow[t]{4}{*}{ YR2009 } & Q1 & 99 & 114 & 118 & 121 & 123 & 123 & 122 & 120 & 116 & 113 \\
\hline & Q2 & 105 & 113 & 115 & 115 & 113 & 111 & 108 & 105 & 102 & 100 \\
\hline & Q3 & 74 & 112 & 113 & 112 & 110 & 108 & 106 & 105 & 104 & 105 \\
\hline & Q4 & 96 & 108 & 105 & 100 & 96 & 91 & 87 & 83 & 80 & 77 \\
\hline \multirow[t]{4}{*}{ YR 2010} & Q1 & 145 & 107 & 103 & 99 & 96 & 93 & 92 & 92 & 93 & 94 \\
\hline & Q2 & 128 & 111 & 111 & 113 & 115 & 119 & 124 & 129 & 135 & 140 \\
\hline & Q3 & 152 & 112 & 115 & 117 & 120 & 124 & 126 & 128 & 129 & 129 \\
\hline & Q4 & 108 & 116 & 122 & 128 & 133 & 138 & 142 & 145 & 147 & 150 \\
\hline \multirow[t]{4}{*}{ YR 2011} & Q1 & 90 & 115 & 119 & 122 & 123 & 123 & 122 & 119 & 116 & 112 \\
\hline & Q2 & 118 & 113 & 114 & 112 & 110 & 106 & 103 & 99 & 95 & 92 \\
\hline & Q3 & 116 & 113 & 114 & 114 & 113 & 112 & 112 & 112 & 113 & 115 \\
\hline & Q4 & 83 & 114 & 115 & 115 & 114 & 114 & 114 & 115 & 115 & 116 \\
\hline \multirow[t]{4}{*}{ YR 2012} & Q1 & 93 & 111 & 108 & 105 & 102 & 99 & 96 & 93 & 89 & 86 \\
\hline & Q2 & 92 & 109 & 105 & 101 & 98 & 96 & 94 & 93 & 92 & 92 \\
\hline & Q3 & 120 & 107 & 103 & 99 & 96 & 94 & 93 & 92 & 92 & 92 \\
\hline & Q4 & 97 & 108 & 106 & 105 & 105 & 107 & 109 & 112 & 114 & 117 \\
\hline \multirow[t]{4}{*}{ YR 2013} & Q1 & 112 & 107 & 104 & 103 & 102 & 102 & 102 & 101 & 100 & 99 \\
\hline & Q2 & 99 & 108 & 106 & 105 & 106 & 107 & 108 & 109 & 110 & 111 \\
\hline & Q3 & 100 & 107 & 104 & 104 & 103 & 103 & 103 & 102 & 101 & 100 \\
\hline & Q4 & 78 & 106 & 104 & 102 & 102 & 101 & 101 & 101 & 100 & 100 \\
\hline \multirow[t]{4}{*}{ YR 2014} & Q1 & 130 & 103 & 98 & 95 & 92 & 90 & 87 & 85 & 82 & 80 \\
\hline & $\mathrm{Q} 2$ & 121 & 106 & 105 & 106 & 107 & 110 & 113 & 116 & 120 & 125 \\
\hline & Q3 & 87 & 108 & 108 & 110 & 113 & 115 & 118 & 120 & 121 & 121 \\
\hline & Q4 & 48 & 105 & 104 & 103 & 103 & 101 & 99 & 97 & 94 & 90 \\
\hline \multirow[t]{2}{*}{ YR 2015} & Q1 & 160 & 100 & 93 & 87 & 81 & 75 & 69 & 63 & 57 & 52 \\
\hline & Q2 & 69 & 106 & 106 & 109 & 112 & 117 & 123 & 131 & 139 & 149 \\
\hline
\end{tabular}


Statistical Analysis of Breast Cancer Cases in University College Hospital (UCH) Ibadan, Nigeria

\begin{tabular}{|c|c|c|c|c|c|c|c|c|c|c|c|}
\hline & Q3 & 86 & 102 & 99 & 97 & 95 & 93 & 91 & 88 & 83 & 77 \\
\hline & Q4 & 107 & 100 & 96 & 94 & 91 & 90 & 88 & 86 & 85 & 85 \\
\hline YR 2016 & Q1 & 114 & 101 & 98 & 98 & 98 & 98 & 99 & 101 & 103 & 105 \\
\hline & Q2 & 95 & 102 & 101 & 103 & 104 & 106 & 108 & 110 & 112 & 113 \\
\hline & Q3 & 87 & 102 & 100 & 100 & 101 & 101 & 100 & 100 & 98 & 97 \\
\hline & Q4 & 109 & 100 & 98 & 96 & 95 & 94 & 92 & 91 & 89 & 88 \\
\hline YR 2017 & Q1 & 107 & 101 & 100 & 100 & 101 & 101 & 102 & 104 & 105 & 107 \\
\hline & Q2 & 141 & 102 & 101 & 102 & 103 & 104 & 105 & 106 & 107 & 107 \\
\hline & Q3 & 157 & 106 & 109 & 114 & 118 & 123 & 127 & 130 & 134 & 138 \\
\hline & Q4 & 164 & 111 & 119 & 127 & 134 & 140 & 145 & 149 & 152 & 155 \\
\hline
\end{tabular}

Source: Authors' computation

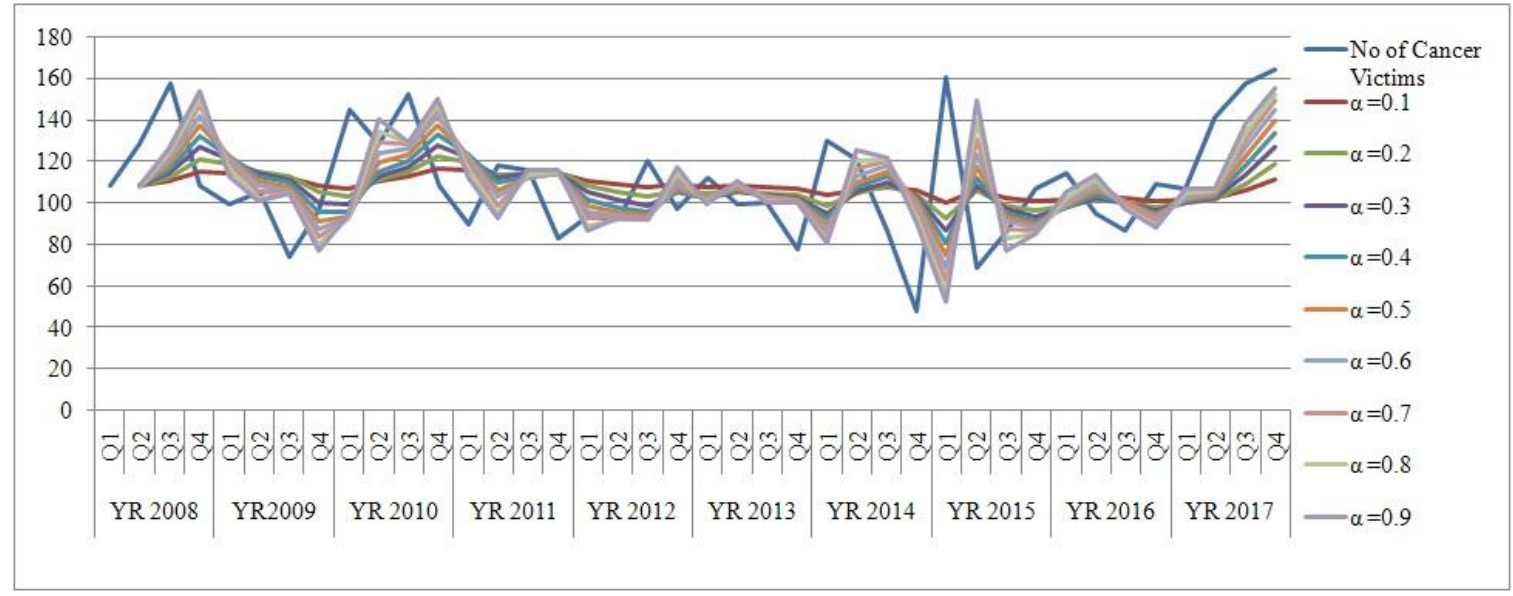

Figure3. Trend analysis of interpolated forecast of breast cancer using simple exponential smoothing

Interpolated Forecast of Breast Cancer Using Ordinary Least Square (OLS) Regression

Equation (3) in the model specification has to do with forecasting method using OLS regression. In order to derive the interpolated forecasts, the variables will be first substituted into equation 4 and 5. Details are shown in Table 4 and Table 5. From the regression line in Figure 4, it can be seen that the rate of breast cancer occurrence tend rising, hence the need for urgent attention to minimize the occurrence of breast cancer cases.

Table4. Details of regression arithmetic

\begin{tabular}{|c|c|c|c|c|}
\hline YEAR & Number of Quarters (x) & No of Cancer Victims (y) & $\mathbf{x y}$ & $\mathbf{x}^{\mathbf{2}}$ \\
\hline YR 2008 & 1 & 108 & 108 & 1 \\
\hline & 2 & 128 & 256 & 4 \\
\hline & 3 & 157 & 471 & 9 \\
\hline & 4 & 108 & 432 & 16 \\
\hline YR2009 & 5 & 99 & 495 & 25 \\
\hline & 6 & 105 & 630 & 36 \\
\hline & 7 & 74 & 518 & 49 \\
\hline & 8 & 96 & 768 & 64 \\
\hline YR 2010 & 9 & 145 & 1305 & 81 \\
\hline & 10 & 128 & 1280 & 100 \\
\hline & 11 & 152 & 1672 & 121 \\
\hline & 12 & 108 & 1296 & 144 \\
\hline YR 2011 & 13 & 90 & 1170 & 169 \\
\hline & 14 & 118 & 1652 & 196 \\
\hline & 15 & 116 & 1740 & 225 \\
\hline & 16 & 83 & 1328 & 256 \\
\hline YR 2012 & 17 & 93 & 1581 & 289 \\
\hline & 18 & 92 & 1656 & 324 \\
\hline & 19 & 120 & 2280 & 361 \\
\hline & 20 & 97 & 1940 & 400 \\
\hline & 21 & 112 & 2352 & 441 \\
\hline & 22 & 99 & 2178 & 484 \\
\hline
\end{tabular}


Statistical Analysis of Breast Cancer Cases in University College Hospital (UCH) Ibadan, Nigeria

\begin{tabular}{|c|c|c|c|c|}
\hline & 23 & 100 & 2300 & 529 \\
\hline & 24 & 78 & 1872 & 576 \\
\hline YR 2014 & 25 & 130 & 3250 & 625 \\
\hline & 26 & 121 & 3146 & 676 \\
\hline & 27 & 87 & 2349 & 729 \\
\hline YR 2015 & 28 & 48 & 1344 & 784 \\
\hline & 29 & 160 & 4640 & 841 \\
\hline & 30 & 69 & 2070 & 900 \\
\hline & 31 & 86 & 2666 & 961 \\
\hline YR 2016 & 32 & 107 & 3424 & 1024 \\
\hline & 33 & 114 & 3762 & 1089 \\
\hline & 34 & 95 & 3230 & 1156 \\
\hline & 35 & 87 & 3045 & 1225 \\
\hline YR 2017 & 36 & 109 & 3924 & 1296 \\
\hline & 37 & 107 & 3959 & 1369 \\
\hline & 38 & 141 & 5358 & 1444 \\
\hline & 39 & 157 & 6123 & 1521 \\
\hline TOTAL & 40 & 164 & 6560 & 1600 \\
\hline
\end{tabular}

Source: Author' computation

There are 40 pairs of readings $(\mathbf{n}=\mathbf{4 0})$

$4388=40 \mathrm{a}+820 \mathrm{~b}$

(Equation 4)

$\Sigma \mathbf{x}=\mathbf{8 2 0}$

$90130=4388 \mathrm{a}+22140 \mathrm{~b}$

(Equation

$\Sigma y=4388$

$\Sigma x y=90130$

5)

$\Sigma x^{2}=22140$

$\mathbf{a}=\mathbf{- 8 . 5 7}$

$\mathbf{b}=\mathbf{5 . 7 7}$

All calculations into two decimal places

$\Sigma \mathrm{y}=\mathrm{na}+\Sigma \mathrm{xb}$. (Equation 4)

$\Sigma x y=\Sigma x a+\Sigma x^{2} b$ (Equation 5)

To obtain the values of $\mathbf{a}$ and $\mathbf{b}$, substitute the readings above into equations 4 and 5 , and solve

Regression line as shown in the model specification of equation (3) is

$Y=\mathbf{- 8 . 5 7 + 5 . 7 7 x}$

To forecast, $\mathrm{x}$ will be replaced by the number of quarters as shown in table 5 below simultaneously.

Table5. Determination of interpolated forecast for breast cancer using OLS regression

\begin{tabular}{|l|c|c|c|}
\hline YEAR & Number of Quarters (x) & No of Cancer Victims (y) & Regression line (Y) \\
\hline YR 2008 & 1 & 108 & -2.8 \\
\hline & 2 & 128 & 2.97 \\
\hline & 3 & 157 & 14.74 \\
\hline & 4 & 108 & 20.28 \\
\hline YR2009 & 5 & 99 & 26.05 \\
\hline & 6 & 105 & 31.82 \\
\hline & 7 & 74 & 37.59 \\
\hline & 8 & 96 & 43.36 \\
\hline YR 2010 & 9 & 145 & 49.13 \\
\hline & 10 & 128 & 54.9 \\
\hline & 11 & 152 & 60.67 \\
\hline & 12 & 108 & 66.44 \\
\hline YR 2011 & 13 & 90 & 72.21 \\
\hline & 14 & 118 & 77.98 \\
\hline & 15 & 116 & 83.75 \\
\hline & 16 & 83 & 89.52 \\
\hline YR 2012 & 17 & 93 & 95.29 \\
\hline & 18 & 92 & 101.1 \\
\hline & 19 & 120 & 106.8 \\
\hline & 20 & 97 & 112.6 \\
\hline YR 2013 & 21 & 112 & 118.4 \\
\hline & 22 & 99 & 124.1 \\
\hline & 23 & 100 & \\
\hline & & & \\
\hline & & & \\
\hline & & & \\
\hline
\end{tabular}


Statistical Analysis of Breast Cancer Cases in University College Hospital (UCH) Ibadan, Nigeria

\begin{tabular}{|l|c|c|c|}
\hline & 24 & 78 & 129.9 \\
\hline YR 2014 & 25 & 130 & 135.7 \\
\hline & 26 & 121 & 141.5 \\
\hline & 27 & 87 & 147.2 \\
\hline & 28 & 48 & 153.8 \\
\hline YR 2015 & 29 & 160 & 164.5 \\
\hline & 30 & 69 & 170.3 \\
\hline & 31 & 86 & 176.1 \\
\hline & 32 & 107 & 181.8 \\
\hline YR 2016 & 33 & 114 & 187.6 \\
\hline & 34 & 95 & 193.4 \\
\hline & 35 & 87 & 199.2 \\
\hline & 36 & 109 & 204.9 \\
\hline YR 2017 & 37 & 107 & 210.7 \\
\hline & 38 & 141 & 216.5 \\
\hline & 39 & 157 & 222.2 \\
\hline
\end{tabular}

Source: Authors' computation

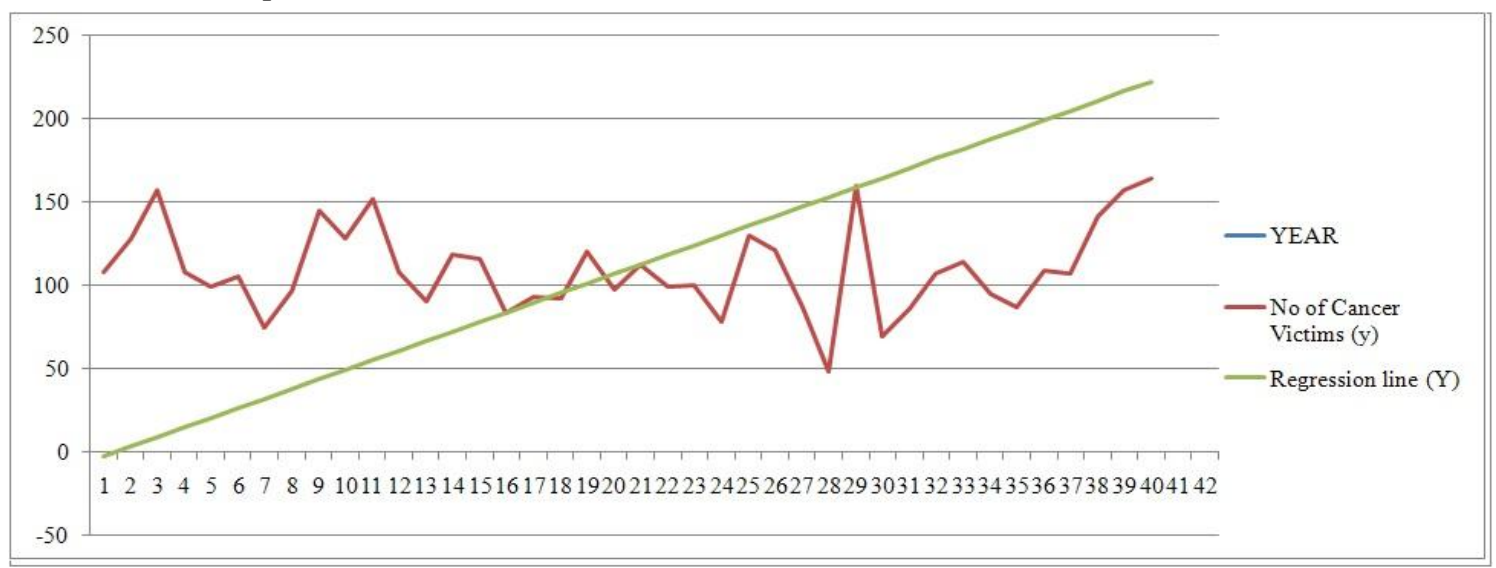

Figure4. Trend of breast cancer victims and regression line

\section{Evaluation of Interpolated Forecast}

In order to get the most suitable interpolated forecast for extrapolation of breast cancer cases reported, there is need to evaluate the most suitable forecast. This is done by comparing yearly single moving averages with exponential smoothing of various smoothing constants, and Ordinary Least Square (OLS) regression using mean absolute deviation (MAD), and Coefficient of determination is the reliability of forecast derived from interpolated forecast.

From Table 6 and Figures 5 and 6 for reported cases of breast cancers in Nigeria, it was revealed that 2 yearly moving average $(n=2)$ and 3 yearly moving average $(n=3)$ are most accurate, as they has lowest value of Mean Absolute Deviation (MAD). Also for exponential smoothing, the smoothing constant of 0.9 appears to be the lowest value of Mean Absolute Deviation (MAD). Hence, it can be deduced from the result that the lower than for the single moving average, the more realistic or reliable the forecast. This corroborates the views of Hsiao (2003), Wooldridge (2001) and Adeniran (2019). Also, the higher the exponential smoothing constant, the more realistic the forecast. This agrees with the the study of Hossein (2015); Lucey (2007); Montogomery \& (1997); Kahn \& Mentzer (1995). It further corroborates the study of Brown (1963) which stated that the higher the values of smoothing constant nearer to 1 , the more sensitive the forecast becomes the current condition.

Table6. Mean Absolute Deviation (MAD) for Single Moving Averages and Simple Exponential Smoothing

\begin{tabular}{|l|c|c|c|c|c|c|c|c|c|}
\hline $\begin{array}{l}\text { Moving } \\
\text { Average }\end{array}$ & $\mathrm{n}=2$ & $\mathrm{n}=3$ & $\mathrm{n}=4$ & $\mathrm{n}=5$ & $\mathrm{n}=6$ & $\mathrm{n}=7$ & $\mathrm{n}=8$ & $\mathrm{n}=9$ & $\mathrm{n}=10$ \\
\hline MAD & 1.3421 & 1 & 1.611111 & 2.457143 & 2.647059 & 3.878788 & 4.28125 & 3.225806 & 2.566667 \\
\hline $\begin{array}{l}\text { Exponential } \\
\text { Smoothing }\end{array}$ & $\alpha=0.1$ & $\alpha=0.2$ & $\alpha=0.3$ & $\alpha=0.4$ & $\alpha=0.5$ & $\alpha=0.6$ & $\alpha=0.7$ & $\alpha=0.8$ & $\alpha=0.9$ \\
\hline MAD & 2.076923 & 2.564103 & 2.512821 & 2.461538 & 2.230769 & 2.051282 & 1.820513 & 1.897436 & 1.615385 \\
\hline
\end{tabular}

Source: Authors' computation 


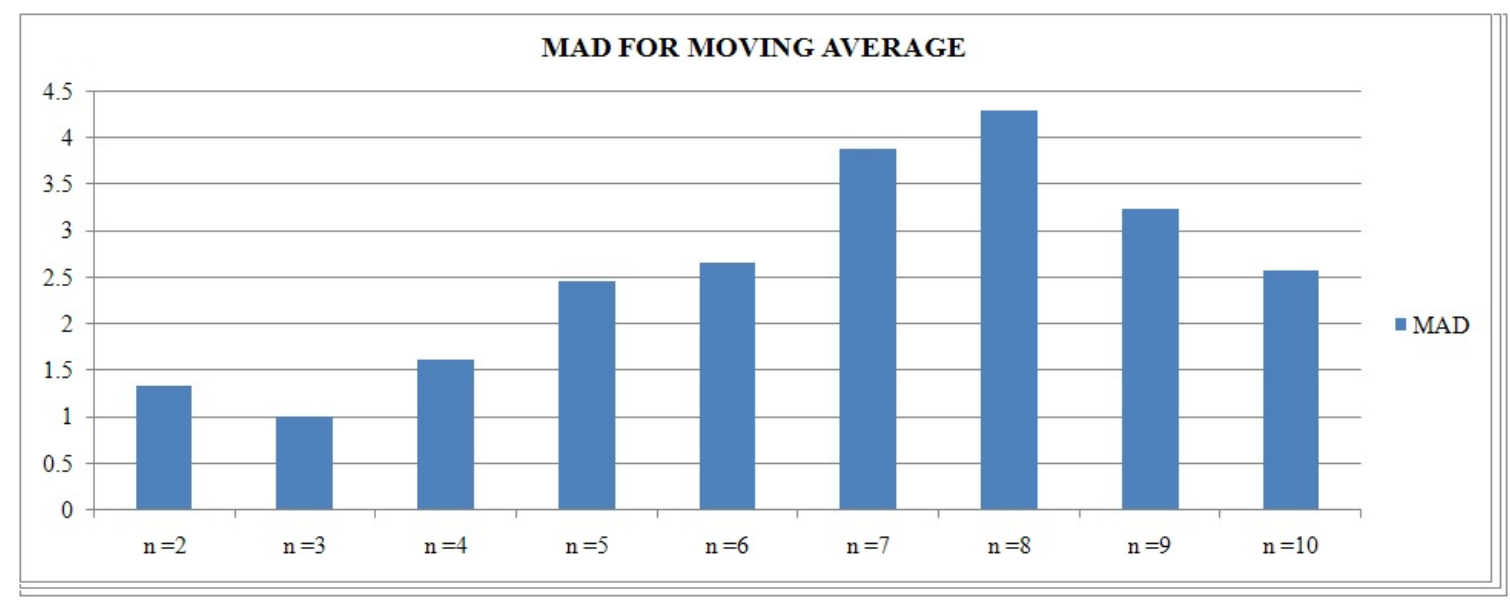

Figure5. Bar chart showing the Mean Absolute Deviation for single moving average

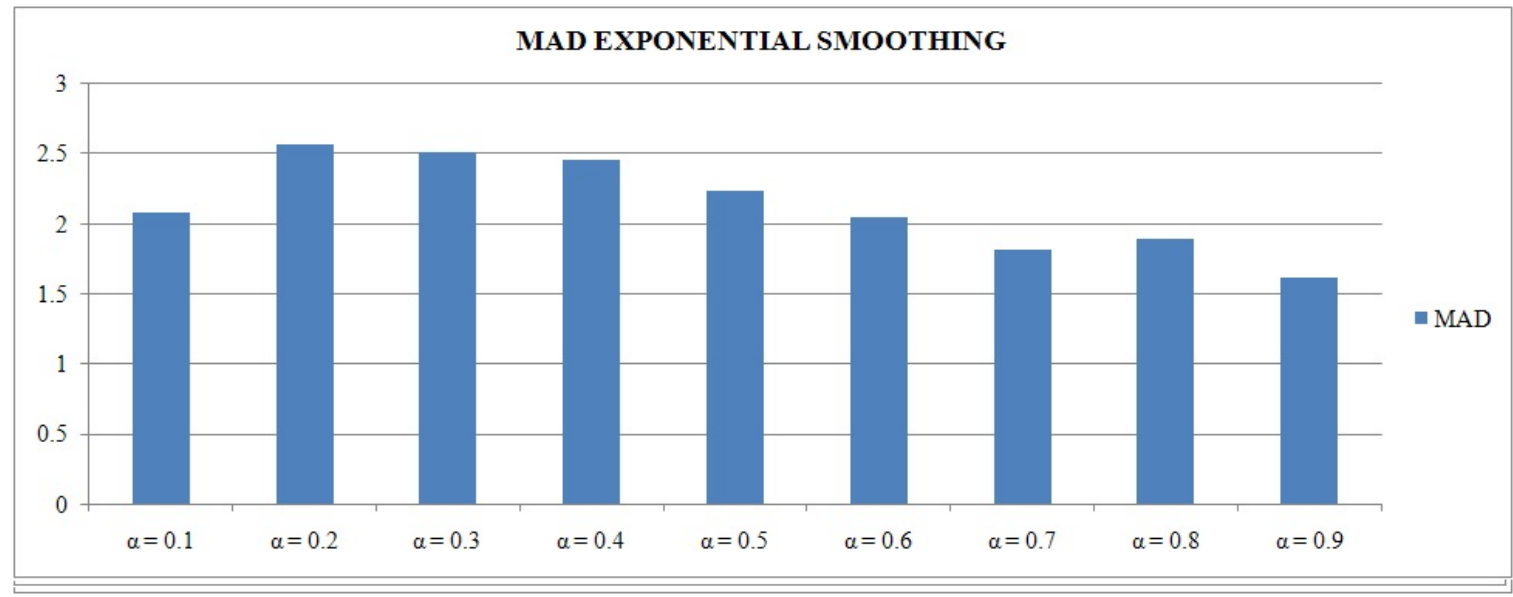

Figure6. Bar chart showing the Mean Absolute Deviation for simple Exponential Smoothing

Calculation test for Ordinary Least Square (OLS) regression reveals that the coefficient of determination $\mathrm{R}^{2}$ is 0.154 . This implies that the 15.4 percent of variations of the actual breast cancer reported may be predicted by changes in the actual number of periods (quarterly). In other words, the factors other than changes in periods influence the cases of breast cancer reported of $(100-15.4)$ percent; 84.6 percent. If the level of explanation be 15.4 percent, then the level of unexplained, or error term, or stochastic disturbance term that is attributed to other factors may be 84.6 percent. This shows that the error term is maximum and very high and the explanation is very low; hence the prediction or forecast by OLS regression seems to be unreliable and that interpolated forecast produced by OLS regression cannot be suitable for extrapolation. This is detailed in Table 7

Table7. Calculation of Coefficient of Determination $\left(R^{2}\right)$ for OLS Regression

\begin{tabular}{|l|c|c|c|c|c|}
\hline YEAR & Number of Quarters (x) & No of Cancer Victims $(\mathbf{y})$ & Forecast $(\mathbf{Y E})$ & $(\mathbf{Y E}-\overline{\mathbf{Y}})^{\mathbf{2}}$ & $\mathbf{( y - \mathbf { Y }}^{\mathbf{2}}$ \\
\hline YR 2008 & 1 & 108 & -2.8 & 12656.25 & 2.89 \\
\hline & 2 & 128 & 2.97 & 11391.29 & 334.89 \\
\hline & 3 & 157 & 8.74 & 10192.92 & 2237.29 \\
\hline & 4 & 108 & 14.51 & 9061.136 & 2.89 \\
\hline YR2009 & 5 & 99 & 20.28 & 7995.936 & 114.49 \\
\hline & 6 & 105 & 26.05 & 6997.323 & 22.09 \\
\hline & 7 & 74 & 31.82 & 6065.294 & 1274.49 \\
\hline & 8 & 96 & 37.59 & 5199.852 & 187.69 \\
\hline YR 2010 & 9 & 145 & 43.36 & 4400.996 & 1246.09 \\
\hline & 10 & 128 & 49.13 & 3668.725 & 334.89 \\
\hline & 11 & 152 & 54.9 & 3003.04 & 1789.29 \\
\hline & 12 & 108 & 60.67 & 2403.941 & 2.89 \\
\hline YR 2011 & 13 & 90 & 66.44 & 1871.428 & 388.09 \\
\hline & 14 & 118 & 72.21 & 1405.5 & 68.89 \\
\hline
\end{tabular}


Statistical Analysis of Breast Cancer Cases in University College Hospital (UCH) Ibadan, Nigeria

\begin{tabular}{|l|c|c|c|c|c|}
\hline & 15 & 116 & 77.98 & 1006.158 & 39.69 \\
\hline & 16 & 83 & 83.75 & 673.4025 & 712.89 \\
\hline YR 2012 & 17 & 93 & 89.52 & 407.2324 & 278.89 \\
\hline & 18 & 92 & 95.29 & 207.6481 & 313.29 \\
\hline & 19 & 120 & 101.1 & 73.96 & 106.09 \\
\hline YR 2013 & 20 & 97 & 106.8 & 8.41 & 161.29 \\
\hline & 21 & 112 & 112.6 & 8.41 & 5.29 \\
\hline & 22 & 99 & 118.4 & 75.69 & 114.49 \\
\hline & 23 & 100 & 124.1 & 207.36 & 94.09 \\
\hline YR 2014 & 24 & 78 & 129.9 & 408.04 & 1004.89 \\
\hline & 25 & 130 & 135.7 & 676 & 412.09 \\
\hline & 26 & 121 & 141.5 & 1011.24 & 127.69 \\
\hline & 27 & 87 & 147.2 & 1406.25 & 515.29 \\
\hline YR 2015 & 28 & 48 & 153 & 1874.89 & 3806.89 \\
\hline & 29 & 160 & 158.8 & 2410.81 & 2530.09 \\
\hline & 30 & 69 & 170.3 & 3003.04 & 1656.49 \\
\hline & 31 & 86 & 176.1 & 4408.96 & 7.29 \\
\hline YR 2016 & 32 & 107 & 181.8 & 5198.41 & 18.49 \\
\hline & 33 & 114 & 193.6 & 6068.41 & 216.09 \\
\hline & 34 & 95 & 199.2 & 8010.25 & 0.49 \\
\hline YR 2017 & 35 & 109 & 204.9 & 9063.04 & 7.29 \\
\hline & 36 & 107 & 210.7 & 10201 & 979.69 \\
\hline & 37 & 141 & 22.2 & 12656.25 & 2948.49 \\
\hline
\end{tabular}

Source: Authors' computation

$\overline{\mathbf{Y}}=\mathbf{1 0 9 . 7}(\mathrm{YE}-\overline{\mathbf{Y}})^{2}=4436.5697(\mathrm{y}-\overline{\mathbf{Y}})^{2}=\mathbf{6 8 4 . 4 6} \mathrm{R}^{2}=\mathbf{0 . 1 5 4}$

\section{CONCLUSIONS AND RECOMMENDATIONS}

In line with the objectives, it is concluded that:

1. Two yearly moving average $(n=2)$ and the yearly moving average $(n=3)$ are most accurate, as they has lowest value of Mean Absolute Deviation (MAD).

2. Exponential smoothing, the smoothing constant of 0.9 appears to be the lowest value of Mean Absolute Deviation (MAD).

3. There is maximum error term and the explanation is very low; hence the prediction or forecast by OLS regression seems to be unreliable and that interpolated forecast produced by OLS regression cannot be suitable for extrapolation.

From the study, it was recommended that the lower than for the single moving average, the more realistic or reliable the forecast. Also, the higher the values of smoothing constant nearer to 1 , the more sensitive the forecast becomes the current condition.

\section{REFERENCES}

[1] Adeniran, A. O. (2019). Analytical Study of Evaluating Forecasting Methods in Nigerian Airport. International Journal of Tourism \& Hotel Business Management (IJTHBM), 1(1), 32-56.

[2] Adeniran, A. O. and Kanyio, O. A. (2018). Long-Term Forecasting of International Air Travel Demand in Nigeria (2018-2028). American International Journal of Multidisciplinary Scientific Research, 1(2), 2531. doi: 10.54655/aijmsr.v1n2p16

[3] Adeniran, A. O., Kanyio, A. O., and Owoeye, A. S. (2018). Forecasting Methods for Domestic Air Passenger Demand in Nigeria. Journal of Applied Research in Industrial Engineering. Vol. 5, No. 2, Pp. 146-155. DOI: 10.22105/jarie.2018.133561.1038

[4] Adeniran, A. O, and Stephens, M. S. (2018). The Dynamics for Evaluating Forecasting Methods for International Air Passenger Demand in Nigeria. Journal of Tourism and Hospitality, 7(366), 1-11. doi: 10.4172/21670269.1000366

[5] Afolayan, E. A. O. (2008). Cancer in North Western region of Nigeria: An update, analysis of Zaria cancer registry data, Western Nigeria. Journal of Medical Science, 1, 37-43.

[6] Afolayan. E, O., Ibrahim, O. O., \& Ayilaran, G. T. (2012). An analysis of Ilorin cancer registry 
statistics. The Tropical Journal of Health Sciences, 9, 42-47.

[7] Agboola, A. J., Musa, A. A., Wanangwa, N., Abdel-Fatah, T., Nolan, C. C., Ayoade, B. A.,\& Ellis, I. O. (2012). Molecular characteristics and prognostic features of breast cancer in Nigeria compared with UK women. Breast Cancer Research and Treatment, 135(2), 555569. doi:10.1007/s10549-012-2173-7

[8] Anderson, B. O., Yip, C. H., Smith, R. A., Shyyan, R., Sener, S. F., \& Eniu, A., et al. (2008). Guideline implementation for breast healthcare in low-income and middle-income countries: Overview of breast the Breast Health Global Initiative Global Summit 2007. Cancer, 113(Supplement), 2221-2243.

[9] Anderson. B. O. (2008). The breast health global initiative: Why it matters to all of us. Oncology, 30(24), 1230-1238.

[10] Boyle . P., \& Levin. B (2008). International Agency for Research on Cancer. World Cancer Report; Lyon, France.

[11] Canadian Cancer Society's Advisory Committee on Cancer Statistices (2014). Canadian Statistics 2014, Toronto, ON: Canadian Cancer Society.

[12] Curado, M, P., Edwards, B., Storm, H., Ferly, J., Haenue, M., \& Boyle, P. (2011). Cancer incidence in five continents. IARC Scientific Publications No 160.

[13] Curado, M. P., Volti, L., \& Sortino-Rachoo, A. M. (2009). Cancer registration data and quality indicators in low and middle-income countries: Their interpretation and potential use for the improvement of cancer care. Cancer Causes, 20(5), 751-752. doi. 10.1007/s10552- 9288

[14] Ferlay, J., Shin, H. R., Bray, F., Forman, D., Mathers, C., \& Parkin, D. M. (2010). Estimates of worldwide burden of cancer in 2008: GLOBOCAN 2008. Int J Cancer, 127(12), 2893- 2917. doi: 10.1002/ijc. 25516

[15] Forouzanfar, M. H., Foreman. K. J., Delossantos, A. M. , Lozano, R., Lopez, A. D., Murray, C. J., \& Naghaui, M (2011). Breast and cervical cancers in 187 countries between 1980- 2010: A Systematic Analysis. Lancet, 378(9801), 1461-1486.

[16] Fregene, A., \& Newman, L. A. (2005). Breast cancer in sub-Sahara Africa. How does it relate to breast cancer in African -American women ? Cancer, 103, 1540-1550.

[17] GLOBOCAN (2012). Cancer incidence, mortality and prevalence worldwide. International Agency for Research on Cancer (IARC 2012-2014).

[18] Hudis, A. C. (2014). On the rise globally, mortality declines in the US. Cancer discovery. Retrieved from doi:10.1158/2159-8290.CD NB 2014
[19] Hyndman, R. J., and Koehler, A. B. (2006). Another look at measures of forecast accuracy. International Journal of Forecasting, 22(4): 679-688.

[20] International Agency for Research on Cancer. GLOBOCAN 2008. Cancer fact sheets. Retrieved from: www.globocan.iarc/fr/fact sheet_cncer.asp X\#WOMEN International Agency for Research on Cancer. GLOBOCAN 2012. Cancer fact sheets. Retrieved from: www.globocan.iarc/fr/fact sheet_ cncer. aspX\# WOMEN

[21] Jedy-Agba, E., Curado, M. P., Ogunbiyi, O., Oga, E., Fabowale, T., Igbinoba, F., \& Adebamowo, C. A. (2012). Cancer incidence in Nigeria: A report from population-based cancer registries. Cancer Epidemiology, 36(5), e271e278. Doi: http://dx.doi.org/ 10.1016/j. canep. 2012.04.007.

[22] Jedy-Agba, E. E., Curado, M. P., Oga, E., Samaila, M. O., Ezeome, E. R., Obiorah, C., \& Adebamowo, C. A. (2012). The role of hospital-based cancer registries in low and middle income countries-The Nigerian Case Study. Cancer Epidemiol, 36(5), 430-435. doi: 10.1016/j.canep.2012.05.010

[23] Hossein, A. (2015). Forecasting by smoothing techniques. Retrieved from: https://home. ubalt.edu/ ntsbarsh/Business-stat/otherapplets/ ForecaSmo.htm

[24] Hsiao, C. (2003). Analysis of panel data. Cambridge University Press. 2nd Edn.

[25] Kahn, K.B. and Mentzer, J.T. (1995). Forecasting in consumer and industrial markets. Journal of Business Forecasting Methods \& Systems, 14, 21-28.

[26] Lucey, T. (2007). Quantitative Techniques. Sixth Edition, 2007. Book Power/ELST.

[27] Mahmoud, E. (1984). Accuracy in forecasting: A survey.Journal of Forecasting,3(2): 139-159.

[28] Makridakis S. (1993). Accuracy measures: theoretical and practical concerns. International Journal of Forecasting, 9(4): 527-529.

[29] Maxmen, A. (2012). The hard facts for women worldwide. Nature Document: URLhttp://go. galegroup. com/ps/ido?.id= GALE\%7CA2 G27 $4351 \& \mathrm{~V}=2.1 \& \mathrm{U}$ England Journal of Medicine, 358, 213-216.

[30] Montgomery, D.C. and Johnson, L.A. (1997). Forecasting and time series analysis. McGrawHill New York.

[31] Nijat, M., David, E., Peter, F., and Peter, L. (2016). Evaluating Forecasting Methods by Considering Different Accuracy Measures. Procedia Computer Science, 95, 264-271

[32] Powers, D. M. (2011). Evaluation: from precision, recall and F-measure to ROC, informedness, markedness, and correlation. 
[33] Ryu, K, and Sanchez, A. (2003) The Evaluation of Forecasting Method at an Institutional Food Service Dining Facility. Journal of Hospitality and Financial Management, 11: 27-45.

[34] Sokolova M, Lapalme G. (2009). A systematic analysis of performance measures for classification tasks. Information Processing \& Management, 45(4): 427-437.

[35] Sylla, B. S., \& Wild, C. P. (2012). A million Africans a year dying from cancer by 2030. What can cancer research and control offer the continent? International Journal of Cancer, 130(2), 245-250.

[36] Wooldridge, J.M. (2001). Econometric analysis of cross section and panel data. The MIT Press.

[37] Yip, C. P., \& Low, W. Y. (2011). Recognizing symptoms of breast cancer as a reason for delayed presentation in Asian women. The psycho-socio-cultural model for breast cancer symptoms appraisal: Opportunities for interventions. Asian Pacific Journal of Breast Cancer Prevention,12, 1601.

Citation: Oluwadamisi Tayo-Ladega, "Statistical Analysis of Breast Cancer Cases in University College Hospital (UCH) Ibadan, Nigeria”, International Journal of Research Studies in Medical and Health Sciences. 2020; 5(11): 31-45.

Copyright: (C) 2020 Oluwadamisi Tayo-Ladega, This is an open-access article distributed under the terms of the Creative Commons Attribution License, which permits unrestricted use, distribution, and reproduction in any medium, provided the original author and source are credited. 